\title{
Dynamic Estimation of Electrical Demand in Hot Rolling Mills
}

\author{
G. Alonso Orcajo, Josué Rodríguez D., Pablo Ardura G., José M. Cano, Member, IEEE, Joaquín G. \\ Norniella, Rocío Llera T., Diego Cifrián R.
}

\begin{abstract}
This paper proposes a method capable of reproducing the particular operating conditions of a hot strip mill and predicting the evolution of the main electrical variables from both the characteristics of the steel to be milled and the specific features of the rolling mill. The method analyzes the load torque and the motor speed evolution in the stands of the roughing and finishing mill drives, according to the steel to be milled. In this study three types of carbon alloy steel are considered, thus involving dissimilar hardness characteristics. The main stands of the mill, the power network and the filter banks have been modeled. The relationship between the grade of steel and both the electrical demand and various power quality parameters is discussed. The results can be used as a part of an expert system for the automatic estimation of the electrical demand in a hot rolling mill.
\end{abstract}

Index Terms - Electrical demand, finishing mill, hot rolling mill, power system harmonics, roughing mill, steel.

\section{INTRODUCTION}

$\mathrm{S}$ TEELMAKING is an energy-intensive process. Although the majority of energy is consumed by the upstream processes (e.g. blast furnaces, basic oxygen furnaces and electrical arc furnaces), the energy consumption in the downstream mills is far from insignificant. Out of the downstream processes, the hot rolling operation is certainly the largest consumer of energy, both in the form of fuel gas and electricity.

The electrical consumption in the hot rolling operation is more than $70 \mathrm{kWh} / \mathrm{ton}$. The main consumers are the rolling stands and the coilers. However, auxiliary equipment cannot be neglected because it represents $25 \%$ of the electrical energy [1], [2].

Paper 2015-METC-0373, presented at the 2015 IEEE Industry Applications Society Annual Meeting, Dallas, Texas, October 19-22, and approved for publication in the IEEE TRANSACTIONS ON INDUSTRY APPLICATIONS by the Metals Committee of the IEEE Industry Applications Society. Manuscript submitted for review July 15, 2015 and released for publication February 3, 2016. This work was supported in part by the Research and Development Center of ArcelorMittal (Avilés, Spain), and the Ministry of Economy and Competitiveness of Spain (project within the framework of the National Plan of Research, Development and Innovation, reference ENE2014-52272-R).

G. Alonso Orcajo, Josué Rodríguez D., José M. Cano and J. G. Norniella are with the Electrical Engineering Department, University of Oviedo, 33204 Gijón, Spain (e-mail: gonzalo@uniovi.es; josue.rodriguez.diez@cern.ch; jmcano@uniovi.es; jgnorniella@uniovi.es ).

Pablo Ardura G., Rocío Llera T. and Diego Cifrián R. are with the Global Research \& Development Department. ArcelorMittal, Avilés, Asturias, 33400, Spain. (e-mail: pablo.ardura@arcelormittal.com; rocio.llera@arcelormittal.com; diego.cifrian@ arcelormittal.com ).
A large part of the steel production costs is due to energy usage. Savings can be achieved by producing in a more efficient way. Furthermore, more energy efficient production processes lead to a reduction of the environmental impact. Therefore, it is useful to identify the energy usage of the production process and also the quality of energy.

Energy is considered to be strategic for the iron and steelmaking sectors. Energy typically represents $15-20 \%$ of the operating costs of a steel plant, and has also direct implications for greenhouse gas regulatory compliance costs. Hot rolling operation represents approximately $8 \%$ of the total energy consumption in an integrated steelworks. Hot rolling is the process with the largest electrical energy demand, accounting for $20 \%$ of the total consumption (approximately $80 \mathrm{kWh} / \mathrm{ton}$ ), and one of the most critical ones in terms of power quality. Not only is the average load considerable, but the dynamic load variation is also large because the mill repeatedly runs through its process cycle [1].

The aim of this paper is to obtain a better understanding of electric energy usage in the hot rolling operation and to define and validate major opportunities for daily energy predictions.

\section{A. Short-time prediction of electrical demand and power quality parameters}

It is crucial to estimate the power demand of a steel plant both in the design stage and under different operating conditions. Estimation allows for guaranteeing the ability of the plant to withstand the anticipated load, calculating the nominal capacity of the lines, designing the protections, etc. Hybrid solutions for filtering and compensating for reactive power are becoming more common in this type of facilities. Such an ad hoc design requires a thorough analysis of reactive power variations and a study of the planned injection of harmonics into the network. Moreover, the aforementioned estimation is necessary to ensure the stability of the voltage at the point of common coupling, the electromagnetic compatibility of the system with the network, the minimization of operation losses and the elimination of penalties from utilities [3].

Most of the electrical variables that characterize power quality and the electromagnetic compatibility of a hot rolling mill are related to the particular rolling conditions at the instant of analysis. Considering the high order of magnitude of the driven power and the strongly non-linear characteristic of the load (Fig. 1), the variability of the conditions has a great impact on the main representative parameters of power quality.

These electrical magnitudes are highly dependent of the rolling process conditions, the chemical composition of the steel slab and the mechanical characteristics that the final coil 


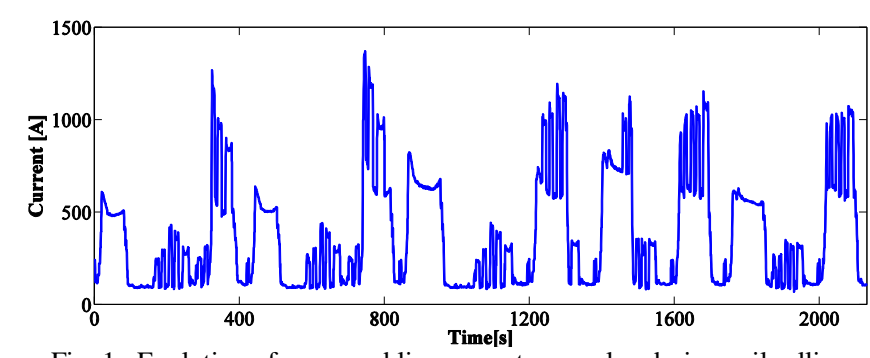

Fig. 1. Evolution of measured line current rms value during coil rolling is intended to have. Hence the interest in developing an analytical method capable of reproducing the particular operating conditions of a hot rolling mill and predicting the evolution of the main electrical variables that are involved.

\section{B. Daily prediction of hot strip mill consumption}

Daily prediction of large facilities consumption allows for significant savings in the cost of electricity. If the energy market liberalization is taken into account, a prediction can be leveraged to improve the negotiation with the utility and obtain more competitive prices in the electricity market.

Therefore, it is crucial to monitor and record (e.g. by using a SCADA system) the electrical variables of the process along with its key operating parameters to predict their influence on the electrical consumption.

However, the high variability of the operating conditions of the process can hamper the drawing of conclusions regarding the independent influence of each variable. Therefore, models that reproduce the operation of the facility as closely as possible are advisable. Such models should be compared to actual variables and validated afterwards. Once validated, the models become an important source of information to identify trends in consumption. These trends can be analyzed by varying a selection of influential variables; such a study is very complicated when conducted just on the basis of field measurements.

\section{HOT ROLLING MILL}

\section{A. Roughing and finishing mills}

The modeled hot rolling mill is a classic facility mainly comprising one roughing and six finishing mill stands (Fig. 2). The behavior of additional equipment such as coiling machines, edgers, crop shear, etc. has not been reproduced in the model because the major consumption of electricity is associated with the roughing and finishing mills.

The roughing mill consists of two stands, one at the top side and the other one at the bottom side. The drives are circulating-current-free and double-cascade-connected cycloconverters. The double-cascade configuration allows for a better power factor by means of asymmetric and bias voltage control. The rated data for the main equipment are shown in Table I.

The finishing mill consists of six stands, three of them (F1, F2 and F3) being driven by means of circulating-current-free, double-cascade-connected, 12-pulse three-phase cycloconverters. The other stands (F4, F5 and F6) are driven from circulating-current-mode, 12-pulse three-phase cycloconverters.

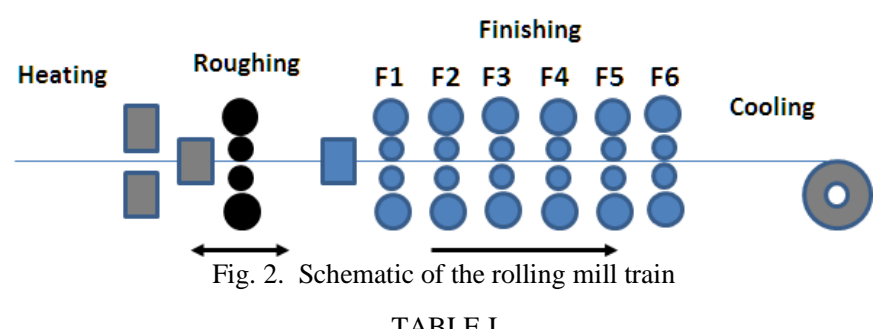

TABLE I

MAIN CHARACTERISTICS OF THE STANDS

\begin{tabular}{ccccc}
\hline STANDS & $\begin{array}{c}\text { MOTOR } \\
\text { POWER } \\
(\text { MW })\end{array}$ & POLES & CYCLOCONVERTER & $\begin{array}{c}\text { TRANSFORMER } \\
\text { POWER(MVA) }\end{array}$ \\
\hline F1 & 8.0 & 6 & Circulating-current-free & 14.4 \\
F2 & 8.0 & 6 & Circulating-current-free & 14.4 \\
F3 & 8.0 & 6 & Circulating-current-free & 14.4 \\
F4 & 8.0 & 6 & Circulating-current-mode & 15.7 \\
F5 & 8.0 & 6 & Circulating-current-mode & 15.7 \\
F6 & 8.0 & 6 & Circulating-current-mode & 15.7 \\
Top Roughing & 7.5 & 12 & Circulating-current-free & 14.4 \\
Bottom Roughing & 7.5 & 12 & Circulating-current-free & 14.4 \\
\hline
\end{tabular}

Circulating-current control allows for the increase of the demand of reactive power when the plant operates at low load.

Since the 1970s, synchronous motors fed by thyristor-based cycloconverters controlled by field oriented control (FOC) have been extensively used in hot rolling mills. Since the 1980s, the trends in steel mill drives have been to use pulse width modulation (PWM)-based voltage source inverters. Despite the technological improvement that the use of inverters involved, in the 1990s, up to ten hot rolling mill lines based on cycloconverters were installed. This technology is used today by many rolling mill plants [4], [5].

The development of new high-power semiconductors and multilevel inverter topologies has led to an increased application of PWM-controlled voltage source inverters (VSI) ranging from 0.5 MVA to approximately $30 \mathrm{MVA}$. Converters for steel mill drives must achieve good dynamic properties and a low torque ripple, control reactive power consumption and harmonic current injection, and be characterized by a high efficiency and adjusted complexity and dimensions. In addition to the application of FOC in inverter-fed motor drives with various PWM schemes, such as carrier-based, hysteresis band control and space vector modulation, the recent application of direct torque control (DTC) to AC drives in plate rolling mills has been claimed as achieving the highest torque and speed performance ever attained with variable speed drives, making it possible to control the full torque within a few milliseconds and reduce the impact of load shocks.

\section{B. Distribution network topology and filtering system}

The hot rolling mill is connected to a $138 \mathrm{kV}, 60 \mathrm{~Hz}$, 3,600 MVA power distribution network through a 75 MVA, $138 / 34.5 \mathrm{kV}$ transformer. The eight stands of the hot rolling mill are fed from a $34.5 \mathrm{kV}$ bus. Four banks of passive filtering are also connected to these same bars. The filtering 
system comprises one C-filter, two second-order high-pass filters and one tuned filter. The global passive filter enables the compensation for $45 \mathrm{Mvar}$ at $34.5 \mathrm{kV}$ (Fig.3). The passive harmonic filter has been designed to improve the harmonic response and provide the reactive power compensation [6].

As shown in Fig. 4, Hcds(s) is the transfer function of a current-divider that considers the relationship between the power system current, Is, and the current injected from the load, I,

$$
H_{c d s}(s)=\frac{I_{s}(s)}{I(s)}=\frac{Z_{f}(s)}{Z_{f}(s)+Z_{s}(s)} .
$$

Fig. 5 shows the attenuation provided by the filtering system in coordination with the impedance of the power distribution system. The transfer function Hcds(s) is based on the single-phase equivalent circuit assuming that the system is balanced [7]. The attenuation factor of the filter bank is mainly effective for high frequencies. Therefore, although high-frequency components are attenuated, some inter-harmonics on the low frequency side are still present and, in some cases, could be amplified due to parallel resonances.

\section{ANALYSIS METHOD}

The developed analysis method is aimed to identify the key variables influencing the electrical behavior of the main stands of a hot rolling mill plant. This process is based on both the characteristics of the steel to be milled and the particular features of the rolling mill. The method provides the evolution of the main electrical variables that are involved.

The demand of active and reactive energy, the consumption of active and reactive power, and the current harmonic injection into the power distribution system are the main variables of interest to be calculated. The results have been compared to the corresponding measurements in an actual rolling plant and then validated.

The main stands of the mill, the power network and the filter banks have been modeled by using a program for simulating electrical power systems [8]. Each stand has been modeled by including a 33/1.15 kV step-down transformer, which converts the 6-pulse topologies of the individual rectifiers to twelve-pulse cycloconverter topologies. Each stand includes six transformers (two transformers per phase). Cycloconverters with their corresponding control stage have also been modeled [9] (bias control, asymmetrical control, circulating current control, etc.), as well as the synchronous motor vector control that determines the modulation index and the phase angle of the control signal.

The load torque developed by the rollers of each stand is applied to the motor (Fig. 6). The control system uses the speed as a reference (Fig. 7). Both variables are subject to the necessary adaptations to the speed-reducer gearboxes and the consequent performance ratio. Therefore, torque and speed are the inputs to the developed electric model.

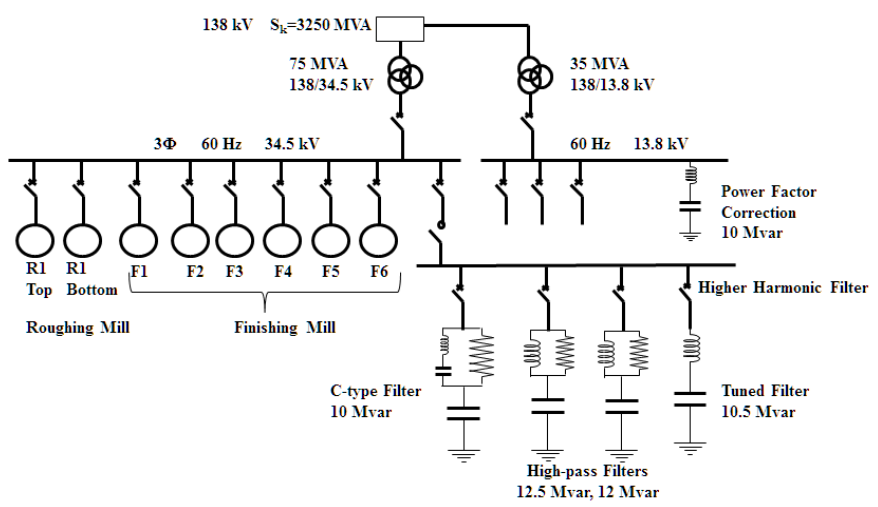

Fig. 3. Single-line diagram distribution network and filtering system

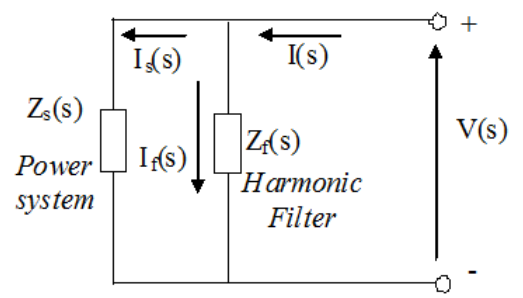

Fig. 4. Current divider based on the filter/system impedance

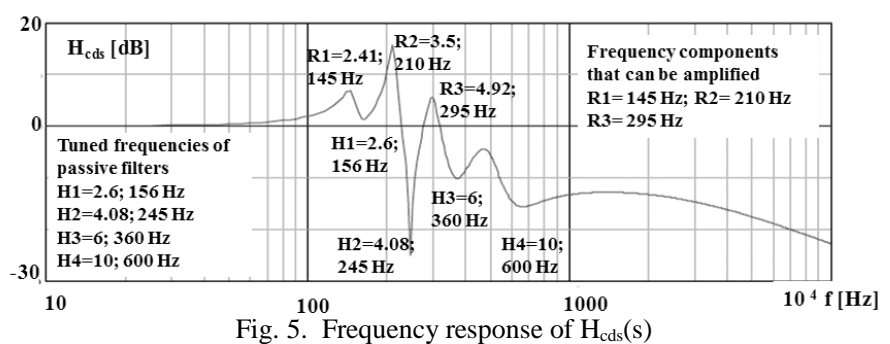

The FOC method is used to control the synchronous motor [10]. This strategy pursues the decoupling of flux and torque control. Therefore, the flux can be mostly fixed by the field windings while the armature current is used to achieve the motor torque. The motor torque is set through a speed control loop that tracks the speed reference and takes the load torque as a disturbance. All of the main loops of the FOC method have been modeled (Park transformations, flux observer, armature current, field current and speed loops, etc.). There are three different control loops:

- Speed loop: To set the flux and motor torque references after tracking the speed reference and performing the field weakening.

- Flux loop: To estimate the flux position through an observer and control the field current.

- Current loop: To track the armature current components (mostly torque current).

The cycloconverter firing signal generator has also been modeled. The voltage reference set by the motor control and the currents are the inputs of the generator and are used for the inhibition of the current-free cycloconverter firing pulses.

Furthermore, the generator uses the cosine-wave crossing technique for the gate signal generation and other secondary control techniques for enhancing the reactive power consumption. Such control techniques are: 


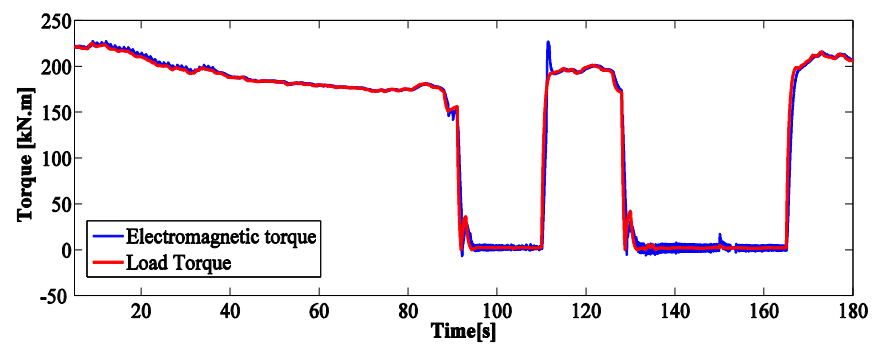

Fig. 6. Calculated electromagnetic torque vs. measured load torque in stand F2

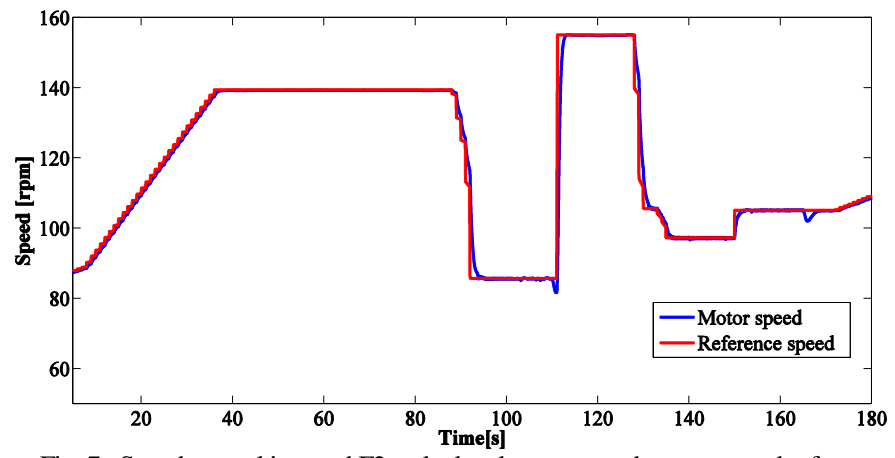

Fig. 7. Speed control in stand F2; calculated motor speed vs. measured reference speed

- Asymmetric control is a strategy used in cascade cycloconverters based on the non-identical firing signals between the two series-connected bridges. The effect is an asymmetric firing in the cascade bridges. It has been implemented in the circulating-free-current cycloconverters (R1, R2, F1, F2 and F3).

- Reactive control through circulating current aims to consume a higher reactive current in the circulatingcurrent-mode cycloconverters (F4, F5 and F6) when the overall reactive consumption of the plant is low (e.g. in the standstills) and the filters overcompensate for the reactive power.

- Bias control aims to achieve voltages with higher rms values at the converter output through third harmonic injection. This kind of control leads to a higher voltage level feeding the motor and, therefore, a decrease of the input reactive power.

\section{TyPES OF STEEL. CHEMICAL AND ALLOY COMPOSITION}

Three grades of steel with different carbon content are considered, thus involving different hardness characteristics. Steel types "A", "B" and "C" have low, medium and high carbon content, respectively. Characteristics of steel are documented in AISI/SAE standard (American Iron and Steel Institute / Society of Automotive Engineers). The chemical composition of each type of steel and its physical and mechanical properties can be obtained from the aforementioned standard (Tables II and III). Standard SAE J403 1010 [11] is used for type "A" steel and Standard SAE J403 1012 [12] for type "B" steel. The SAE standards between 1005 and 1015 are used for steel whose carbon content is between 0.06 and $0.18 \%$. Standard SAE J403 1050 [13] is used for type "C" steel. SAE standards between 1035 and 1053 are used for steel whose carbon content is between 0.32 and $0.55 \%$.

\section{MILL PROCESS. INFLUENCING VARIABLES}

The slab reaches the roughing mill free of mill scale, where it is given the correct thickness to enter the finishing mill train. Five to seven passes are run in the four-high reversing stand to roll the slab down to the required transfer-bar thickness. The number of passes depends on the measurements of the slab, the steel plate to be obtained, the grade of steel and the final rolling temperature in the train. The steel plate leaving the roughing mill train is subject to a single pass in the continuous finishing train, then partially cooled but coiled while still hot. The finishing mill train consists of six nonreversible two-high arrangement stands where the required final thickness is achieved. The temperature varies between $800^{\circ} \mathrm{C}$ and $1,250^{\circ} \mathrm{C}$. Hot rolling must be conducted at the appropriate temperature, both on the surface and inside the material [14], [15].

For the determination of the mechanical conditions of the rolling mill, mathematical models able to interrelate the process variables with the characteristics of the steel sheet are used. The models provide data about reductions in stands, roll speeds, temperature at the end of the last stand, cooling rate, coiling temperature, etc. Several programs allow for estimating the rolling conditions, such as StripCam and HSMM (Hot Strip Mill Model). Both programs are capable of interrelating the rolling process variables with the mechanical properties of the steel to be obtained [15], [16].

\section{SYNCHRONOUS MOTORS LOAD TORQUE AND SPEED}

Rolling conditions for each type of steel are described as follows. The required load torque and speed of the motors are calculated from summarized bellow conditions.

\section{A. Flat rolling}

In flat rolling [17], the thickness is reduced by an amount called the draft,

$$
d=t_{0}-t_{f},
$$

where $d$ is the draft, $t_{0}$ is the starting thickness and $t_{f}$ is the final thickness. When selecting the draft it is necessary to optimize the mill operation within the limits set by the rated power of the motors. The true strain, $\varepsilon$, undergone by the work in rolling depends on the previous and subsequent stock thicknesses,

$$
\varepsilon=\ln \frac{t_{0}}{t_{f}} .
$$

The average flow stress, $\overline{Y_{f}}$, applied to the work material in flat rolling, is determined from the true strain,

$$
\overline{Y_{f}}=\frac{K \cdot \varepsilon^{n}}{1+n} .
$$

Values of the strength coefficient, $K$, and the strainhardening exponent, $n$, depend on the composition, the heat treatment and the work hardening. The higher the carbon content is, the higher the strength coefficient results (Fig. 8). The average flow stress is used to estimate the rolling force and power. 
TABLE II

CHEMICAL COMPOSITION OF THE THREe TyPes OF STEEL

\begin{tabular}{cccc}
\hline Element & Steel $\boldsymbol{A}$ - Content $(\%)$ & Steel $\boldsymbol{B}$ - Content $(\%)$ & Steel C-Content $(\%)$ \\
\hline Iron & $99.3-99.7$ & $99.16-99.6$ & $98.46-98.92$ \\
Manganese & $\leq 0.6$ & $0.3-0.6$ & $0.6-0.9$ \\
Carbon & $\leq 0.12$ & $0.1-0.15$ & $0.47-0.55$ \\
Sulfur & $\leq 0.045$ & $\leq 0.05$ & $\leq 0.05$ \\
Phosphorous & $\leq 0.045$ & $\leq 0.04$ & $\leq 0.04$ \\
\hline
\end{tabular}

TABLE III

\begin{tabular}{|c|c|c|c|}
\hline Properties & Steel A & $\begin{array}{l}\text { Steel B } \\
\end{array}$ & $\begin{array}{l}\text { Steel C } \\
\end{array}$ \\
\hline Tensile strength [MPa] & 325 & 370 & 690 \\
\hline Yield strength [MPa] & $\geq 280$ & 310 & 580 \\
\hline Elastic modulus [GPa] & 210 & $190-210$ & $190-210$ \\
\hline Poisson's ratio & $0.27-0.3$ & $0.27-0.3$ & $0.27-0.3$ \\
\hline Elongation at break [\%] & 28 (in $80 \mathrm{~mm}$ ) & 19 (in $50 \mathrm{~mm}$ ) & 10 (in $50 \mathrm{~mm}$ ) \\
\hline Hardness, Vickers & 105 & 108 & 207 \\
\hline Density $\left[\mathrm{gr} / \mathrm{cm}^{3}\right]$ & 7.872 & 7.87 & 7.85 \\
\hline
\end{tabular}

An approximation of the rolling force, $F$, can be calculated from the average flow stress,

$$
F=\overline{Y_{f}} \cdot w \cdot L,
$$

where $\mathrm{w}$ is the material width and $\mathrm{L}$ is the contact length, which considering $\mathrm{R}$ the roll radius is approximately

$$
L=\sqrt{R \cdot\left(t_{0}-t_{f}\right)} .
$$

The power, $P$, required to drive two powered rolls is twice as much as the product of the torque for each roll and the angular velocity. The torque for each roll, $T$, is

$$
T=0.5 \cdot F \cdot L
$$

and the active power is

$$
P=F \cdot L \cdot \omega_{r},
$$

where $\omega_{r}$ is the rotational speed in radians per second. The active power demanded by the motors must be correctly distributed by choosing the strip thickness at the delivery side of each stand. Temperature and deformation resistance play an important role in the distribution of forces in the stands.

\section{B. Steel types: rolling conditions}

The behavior of the three types of steel has been obtained from their chemical composition (see Table II). Fig. 9 shows $K$-strength coefficient and $n$-strain-hardening exponent at the rolling temperature during the corresponding passes. The strip thickness at the delivery side of each stand has been chosen (Figs. 10 and 11) by considering the constraints on the power and speed of the stands and the measurements of the slab and the rolls (Table IV).

The average flow stress is obtained from (4) and, then, the force and torque applied by each roller are calculated from (5) and (7). Constraints to the speed/frequency and maximum power at the stands must be considered to set the speed of the rolls. The mechanical conditions in Figs. 12 and 13 correspond to rolls data. Speed limits for stands F1 and F2 are observed in Fig. 14. These stands are subject to higher torques in the finishing mill and, therefore, the constraints on speed are more severe. The tensile strength obtained from the estimation of the mechanical rolling conditions is compared to that provided by the standard (Table V).
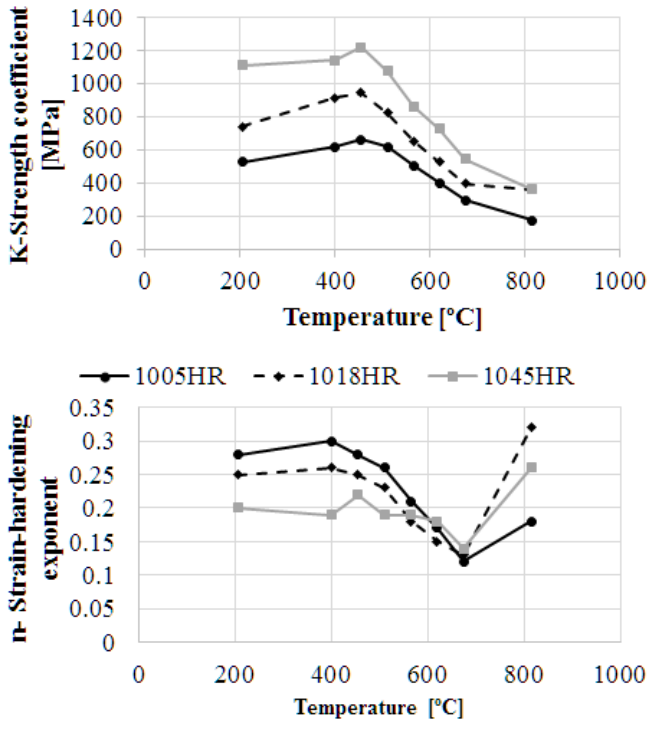

$\rightarrow 1005 \mathrm{HR} \quad--1018 \mathrm{HR} \quad--1045 \mathrm{HR}$

Fig. 8. Typical values of $K$ and $n$ for different types of hot rolled steel [18]

TABLE IV

GEOMETRY OF THE SLAB FOR DIFFERENT TYPES OF STEEL

\begin{tabular}{cccc}
\hline Element & Steel A & Steel B & Steel C \\
\hline Slab length $(\mathbf{m})$ & 10 & 11 & 11 \\
Slab width $(\mathbf{m m})$ & 1,259 & 1,224 & 1,248 \\
Slab weight (ton) & 22.75 & 23.78 & 24.68 \\
\hline
\end{tabular}
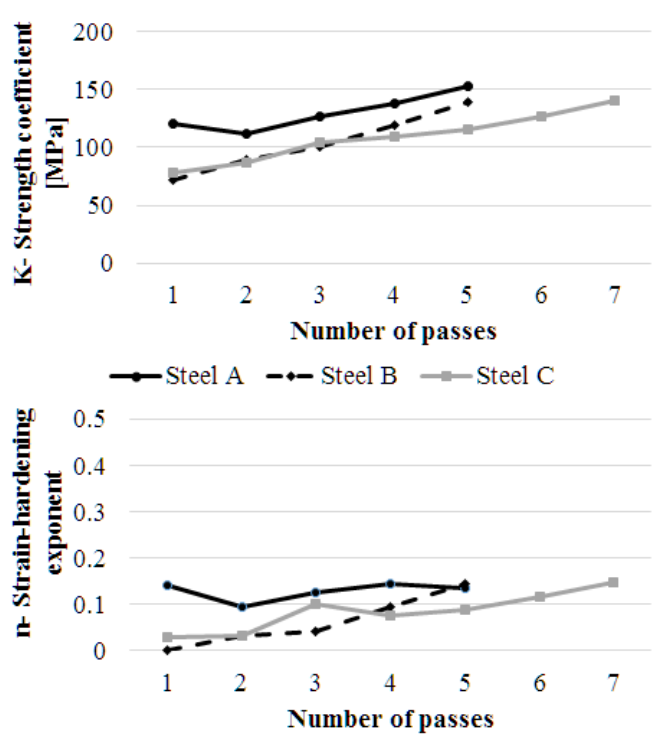

$\longrightarrow$ Steel A $-\leftarrow$ Steel B $\longrightarrow$ Steel C

Fig. 9. Top: K-strength coefficient. Bottom: $n$-strain hardening exponent

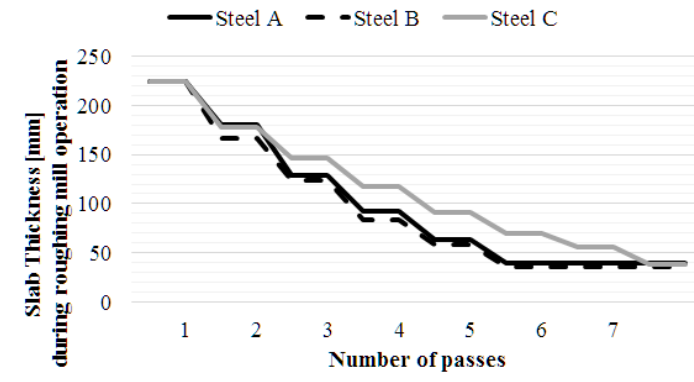

Fig. 10: Calculated thickness of the slab during the passes in roughing mill. 


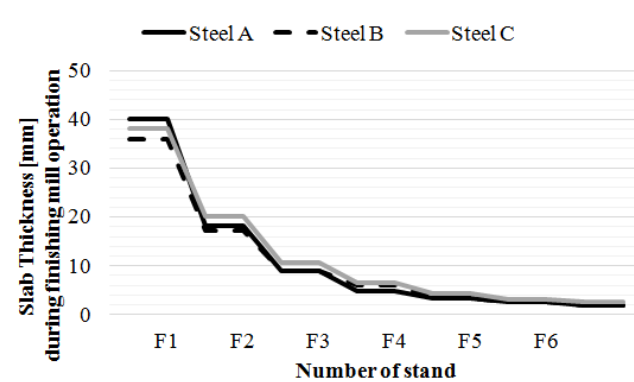

Fig. 11. Calculated thickness of the slab during the passes in finishing mill.
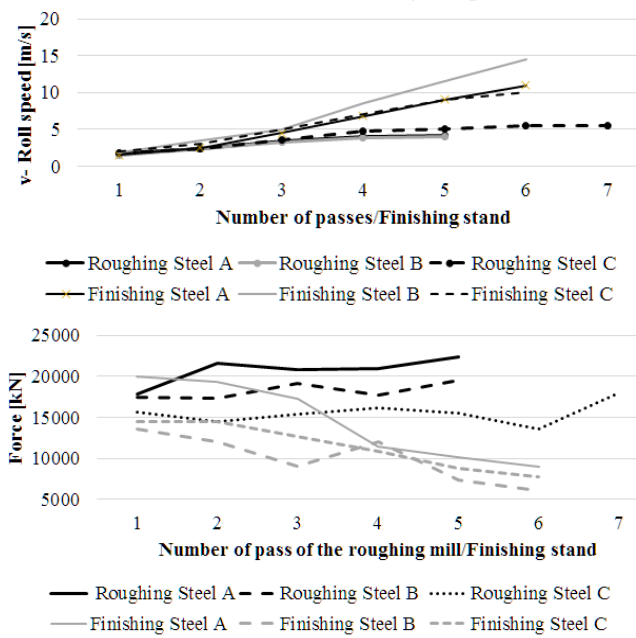

Fig. 12. Top: calculated roll speed during the rolling of steel types A, B and C. Bottom: calculated rolling force during steel mill.

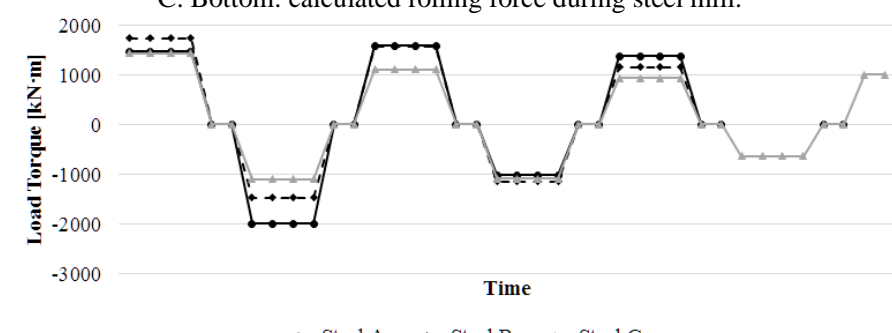

Fig. 13. Calculated load torque of the roughing mill stands during milling of $600 \quad$ different types of steel.

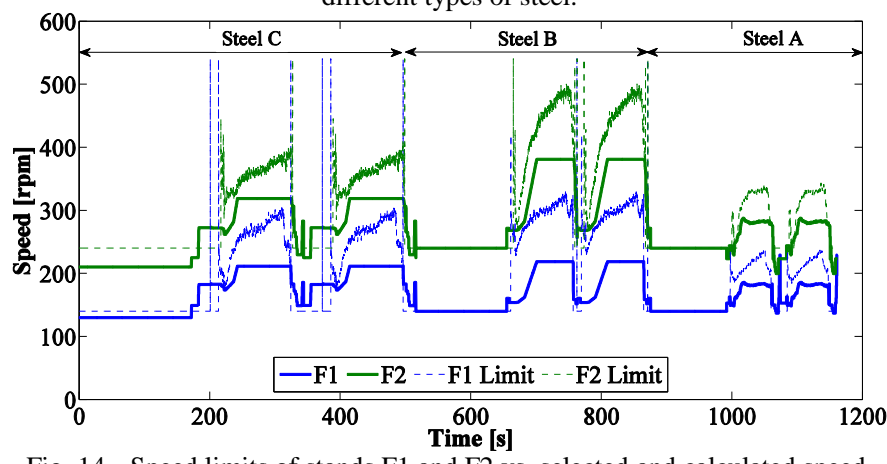

Fig. 14. Speed limits of stands F1 and F2 vs. selected and calculated speed.

Estimation is validated because the values of the tensile strength have the same order of magnitude. The evolution of the load torque and the motor speed at the stands of the roughing and finishing mill drives, corresponding to motor conditions, are shown in Figs. 15 and 16. In the case of the finishing mill the ratios of the gearboxes incorporated into the stands must be considered: $\mathrm{F} 1=5.2 ; \mathrm{F} 2=4.5 ; \mathrm{F} 3=3.0 ; \mathrm{F} 4=1.478: \mathrm{F} 5=1.0$; F6=1.0. The roughing mill does not incorporate any gearboxes.

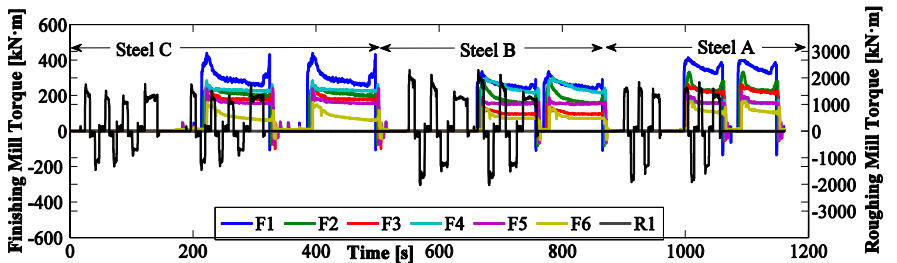

Fig. 15. Measured load torque at the stands during steel milling.

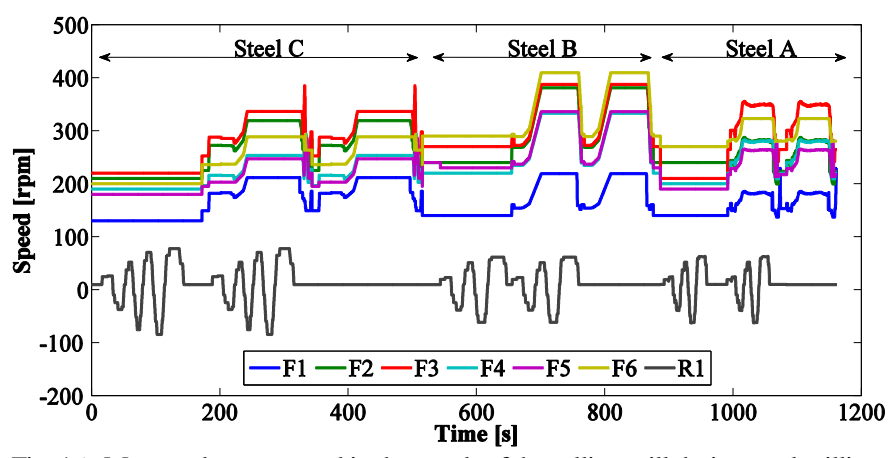

Fig. 16. Measured motor speed in the stands of the rolling mill during steel milling.

TABLE V

VALIDATION OF THE TENSILE STRENGTH FROM SIMULATION

\begin{tabular}{cccc}
\hline Tensile strength & Steel A & Steel B & Steel C \\
\hline Simulation [MPa] & 355 & 352 & 661 \\
Standard [MPa] & 325 & 370 & 690 \\
\hline
\end{tabular}

\section{POWER AND ENERGY DEMAND}

The demanded active power is directly calculated from the values of the torque and speed of the rolling mill motors, the performance ratio of the drives and the transformer and stand line losses. Reactive power values are mainly obtained from the cycloconverter mean trigger angle (Fig. 17). All represented records in this section have been calculated. The analysis procedure has been validated in section VIII using onsite measurements. This angle depends on the load angle, $\phi_{0}$, and the cycloconverter modulation index, $m$. The relationship among the load angle, the modulation index and the displacement factor at the input, $\cos \left(\Phi_{i}\right)$, is as follows [19]:

$$
\cos \left(\phi_{i}\right)=\frac{m}{\sqrt{\left(1+4 \cdot\left(\frac{\cos \left(\phi_{0}\right)+\phi_{0} \cdot \sin \left(\phi_{0}\right)}{\pi \cdot \cos \left(\phi_{0}\right)}\right)^{2}\right)}} .
$$

In the case of synchronous motors fed from the cycloconverters, the output displacement factor is close to unity because vector control forces the synchronous motor to operate with unity power factor. The highest input displacement factor is reached when the output voltage is maximum and, therefore, the modulation index is equal to 1 [20], [21]. At low-modulation index operation (low load), higher values of reactive power are absorbed by the cycloconverter, whereas the active power absorbed by the cycloconverter increases and the reactive power decreases with a high modulation index [22]. The reactive power, $Q$, is estimated from the active power and the input displacement factor,

$$
Q=P \cdot \tan \left(\phi_{i}\right)
$$




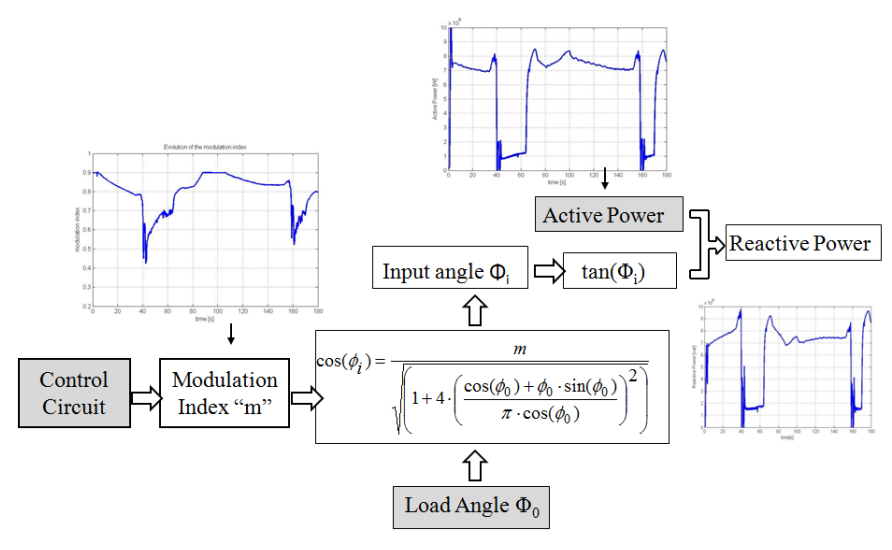

Fig. 17. Flow diagram for calculating reactive power consumption.

The reactive power demand in stands F4, F5 and F6 is controlled by the active control of reactive power [23], [24]. Overcompensation in the distribution network is avoided at low-load intervals because the extra reactive power from the filter banks is demanded by these stands. These stands are forced to consume an extra reactive power, $Q_{0}$, to compensate for the reactive power injection from the filter banks. $Q_{0}$ is calculated by subtracting the reactive power injected by the different filter banks and the reactive power consumed by the stands, which is associated with the particular loading conditions. Such a difference is divided by 3 when positive in order to distribute it among the three stands with circulatory current. Each stand will provide a maximum value of reactive power depending on the maximum power that the converter can drive and the active and reactive power associated with the loading conditions.

Fig. 18 shows four kinds of reactive power: the reactive power associated with the particular loading conditions, the maximum reactive power that the drive can deliver through the circulating current, the reactive power consumption associated with the circulating current and the final demand of reactive power associated with stand $\mathrm{F} 4$.

\section{A. Roughing mill}

In this section, a comparative analysis of the active and reactive power consumption in the roughing mill has been performed (Fig. 19). Type-C steel requires 7 passes.

Steel types A and B require only 5 passes. The maximum consumption is limited by the maximum power that the drives can deliver. Both active and reactive energy increase with the steel hardness. The demand of active energy for type-C steel is $39 \%$ greater than that required for type-A steel.

\section{B. Finishing mill}

The study conducted for the roughing mill is also performed for the finishing mill train (Fig. 20). In this case, the maximum values of active power demand have the same order of magnitude and the difference between the types of steel relies on the duration of the mill period. Fig. 19 shows a difference of 20 s over a maximum period of $120 \mathrm{~s}$.

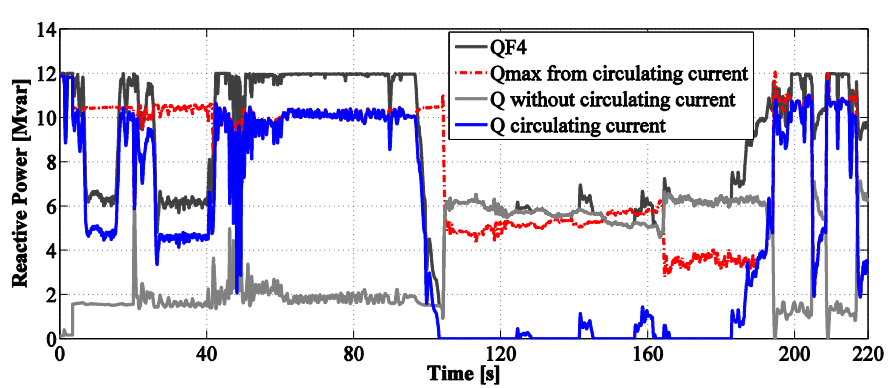

Fig. 18. Evolution of reactive power demands at stand F4.

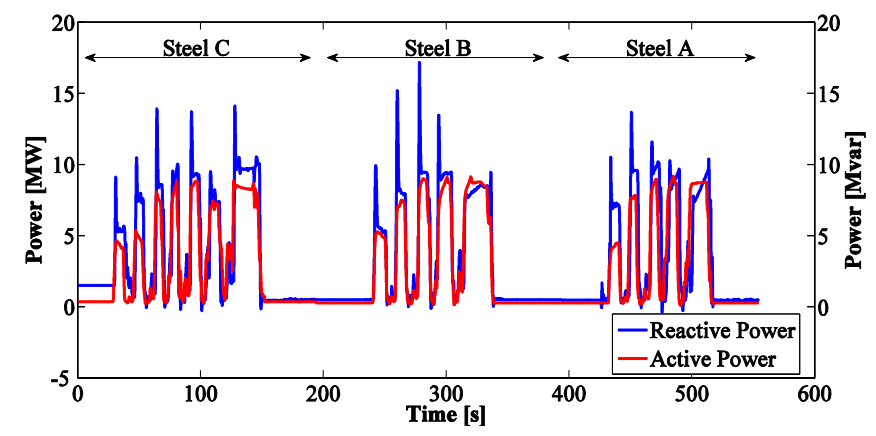

Fig. 19. Active and reactive power demanded by top roughing mill drive

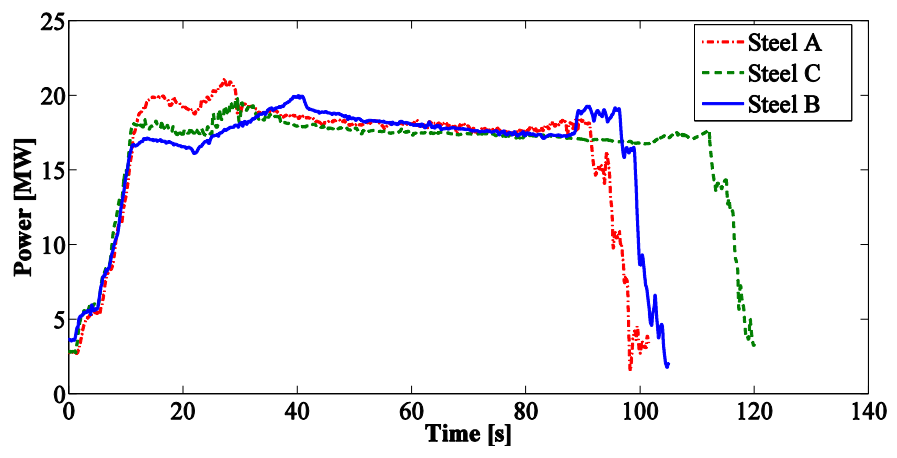

Fig. 20. Active power demanded by the finishing mill.

\section{Global demand}

Possible overlapping of roughing and finishing mill trains must be considered for a global analysis of the demand. When overlapping does not occur, the consumption is sequential and the demands of active and reactive power are those corresponding to these trains, although not synchronized.

Fig. 21 shows the active and reactive power flow downstream and upstream of the point of common coupling PCC .These variables are used to estimate the energy demand (Fig. 22) and the evolution of the rms value of the current and voltage (Fig 23). Knowledge of the evolution of the rms value of the voltage at the coupling point is crucial to ensure compliance with the requirements set by standards [25].

The frequency components of the currents demanded by the stands are dependent of the number of converter pulses and the output frequency of the cycloconverter, and, the motor speed. The amplitudes and phase angles of these components are quantities that depend fundamentally on the analyzed frequency, the modulation index of the cycloconverter and the filtering inductive impedances of the circuits [21]. 


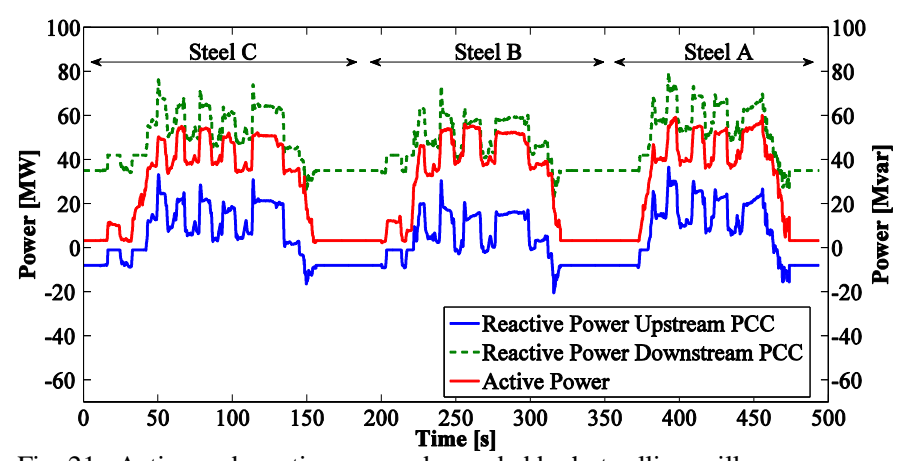

Fig. 21. Active and reactive power demanded by hot rolling mill.

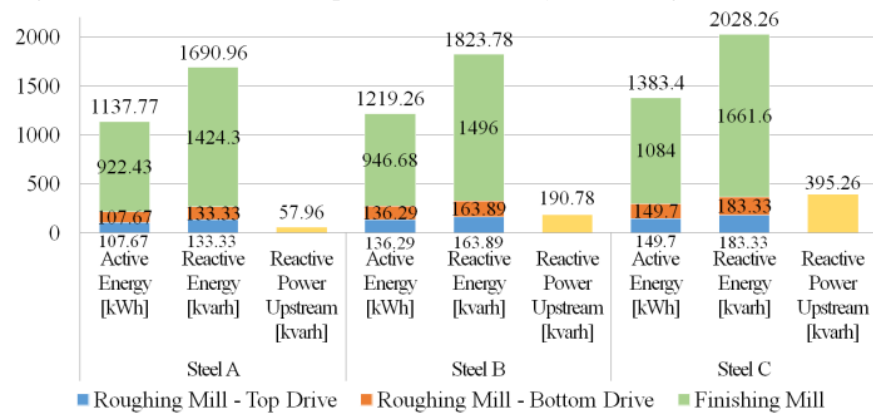

Fig. 22. Active and reactive energy demanded by hot rolling mill.
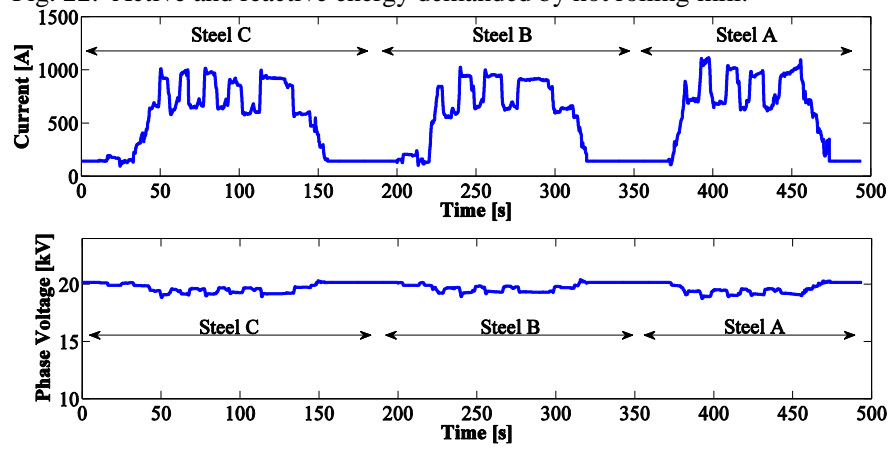

Fig. 23. Evolution of the rms value of the current upstream of the PCC and of the phase voltage at the PCC.

The frequency components from the stands, along with the frequency response of the filter stage and the distribution network (Fig. 5), allow for performing the analysis of the dynamic evolution of the total harmonic distortion of the voltage at the coupling point (Fig 24).

\section{VALIDATION OF THE RESULTS}

The validation of the electric model is demonstrated by comparing its results with on-site measurements during the rolling of type "A" steel. To obtain the calculated variables, the rolling process is simulated and the main variables are estimated according to the flowchart shown in Fig.25 [26].The evolution of the main electrical variables for the same type of steel is shown in Figs. 26-28, which is obtained from on-site measurements, is compared with the similar evolution of the calculated variables.

The sampling frequency is $25 \mathrm{kHz}$ for the calculated variables and $100 \mathrm{~Hz}$ for the measured variables. The measured THD of the voltage is a time-averaged record, whereas the calculated THD has been obtained at a higher registering frequency. Because torque and speed, which feed the model, experience a significant change in the process that is reproduced, the electrical variables also experience significant dynamic variations.

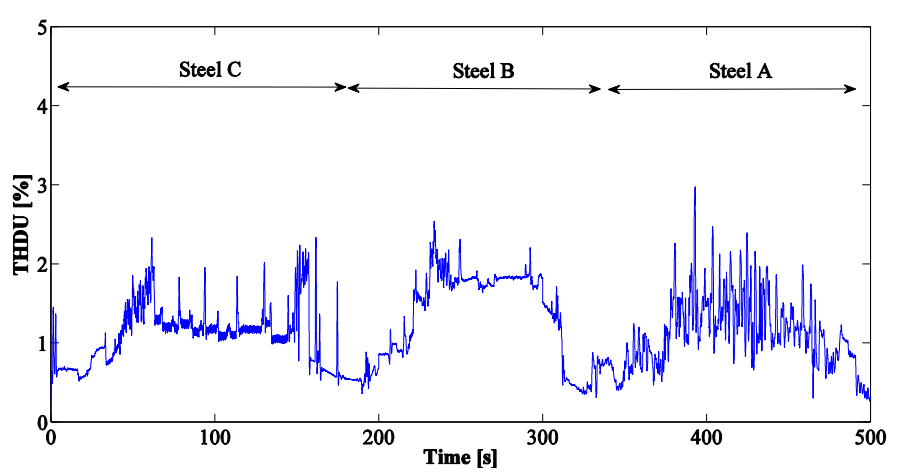

Fig. 24. Evolution of the voltage THD at the PCC.

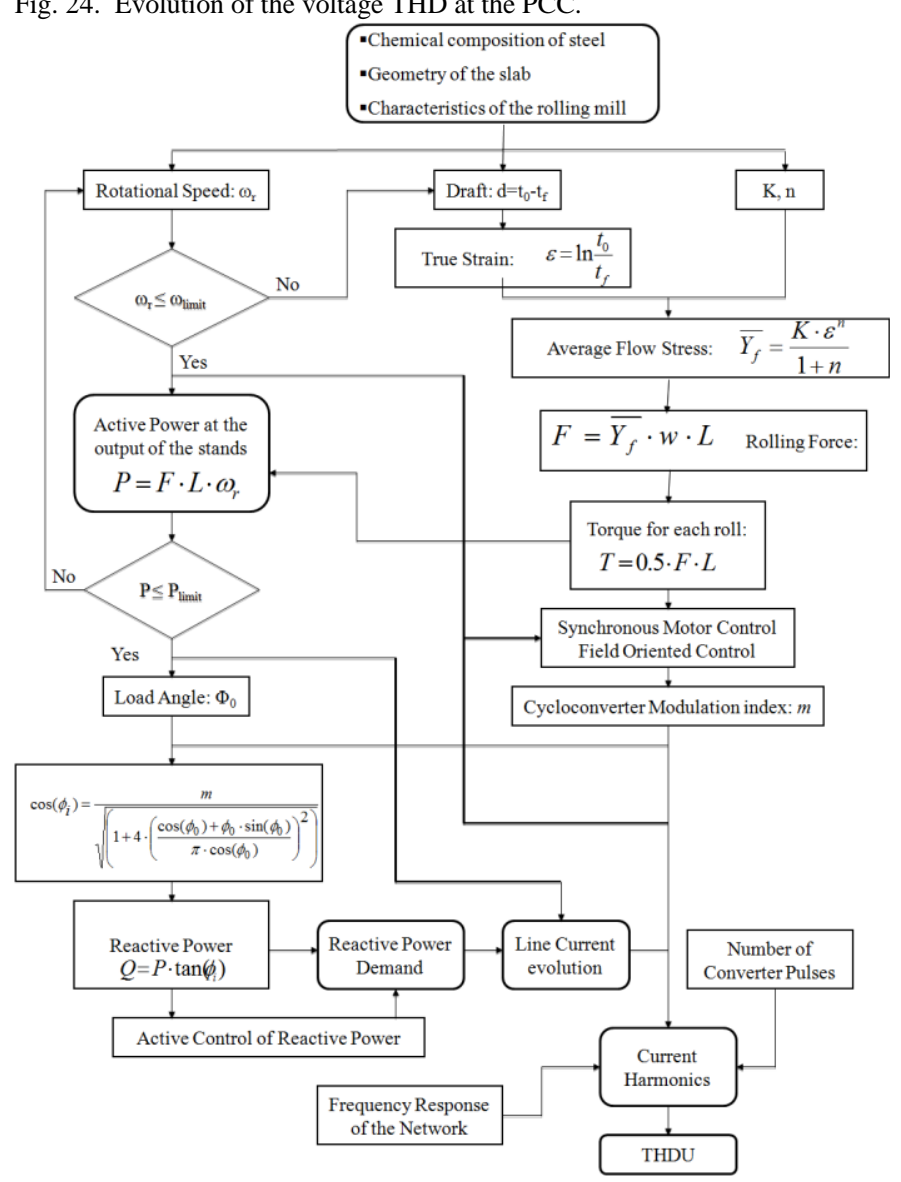

Fig. 25. Simplified flowchart to estimate the main variables.

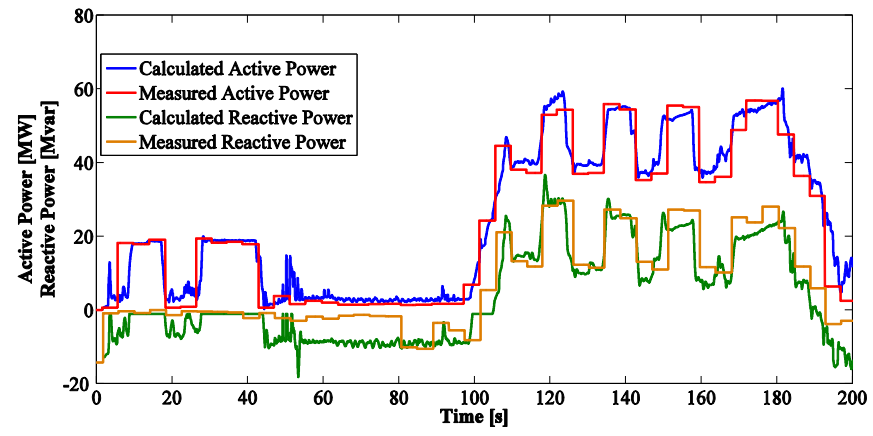

Fig. 26. Validation of active and reactive power demanded by rolling mill.

The achieved adjustment as shown in the Figs. 26-28 is accurate. The major discrepancies occur at periods of low load, due to the fact that only the most significant loads have been modeled (finishing and roughing mill) and the impact of these discrepancies is not relevant to the overall analysis. 

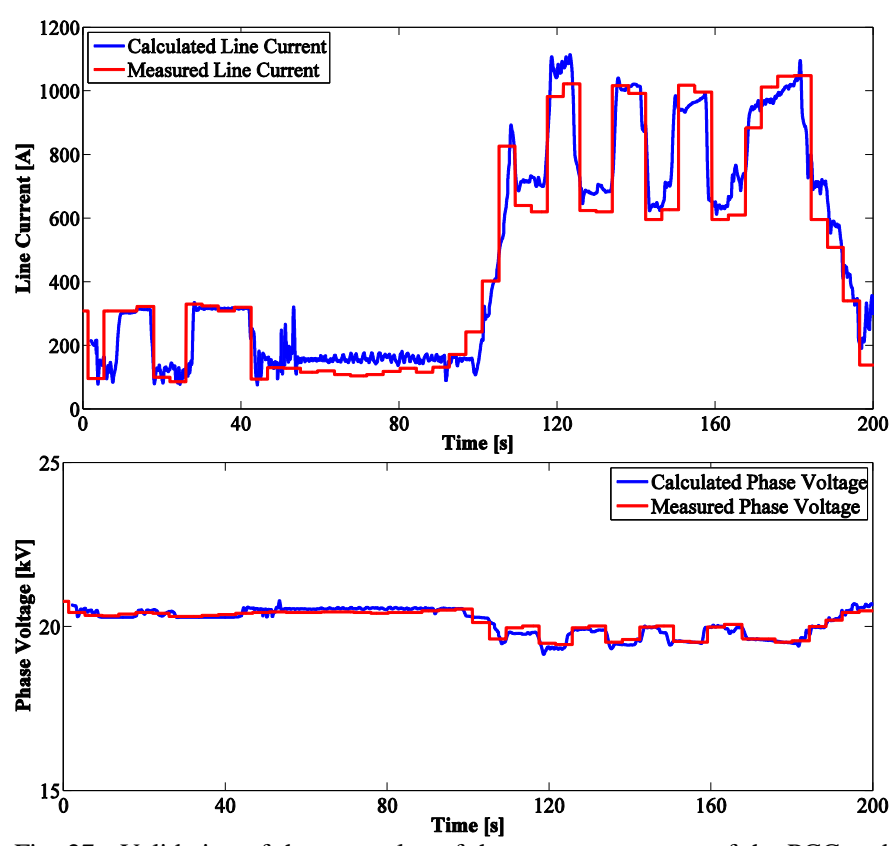

Fig. 27. Validation of the rms value of the current upstream of the PCC and of the phase voltage at the PCC.

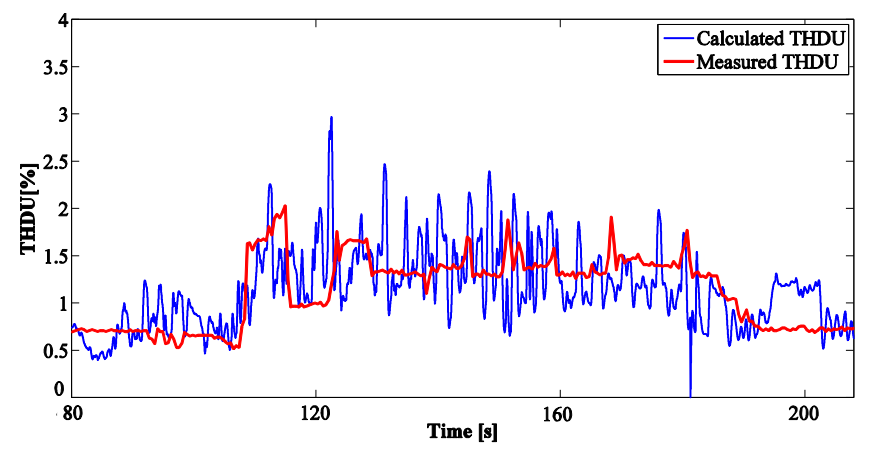

Fig. 28. Validation of the voltage THD at the PCC.

\section{CONCLUSION}

The relationship among the properties of the steel to be milled, the mechanical conditions of the rolling mill, the technical features of the roughing and finishing mills and the involved electrical variables has been obtained. The proposed method provides a powerful analytical tool for the prediction of the electrical demand and the power quality parameters. The continuous variability of the process operating conditions can hinder the drawing of conclusions from actual measurements regarding the independent influence of each variable.

A complete hot strip mill facility has been modeled. Each stand of the roughing and finishing mills has been simulated. The electric distribution system of the factory with the existing passive filtering stage has been modeled as well. The model has been tested with several load profiles by using the torque and speed variables as input data, and with on-site measurements of voltage, current, active and reactive power, torque and rolling speed. A database with three steel types has been analyzed, which allows for correlating the type of steel with the electrical demand and several power quality parameters. A simple algorithm has been developed to set a correlation between the mill operation conditions and the electrical demand of the facility. The influence of several mechanical variables and electrical variables on power demand and power quality has been analyzed.

\section{REFERENCES}

[1] E. Kun, T. Szemmelveisz, "Energy efficiency enhancement in the Hot Rolling Mill” Materials Science and Engineering, vol. 3, no. 2, pp. 4350, 2014.

[2] University of Oviedo, Arcelormittal Spain, Centre de Recherches Metallurgiques ASBL, Vdeh-Betriebsforschungsinstitut Gmbh, "Minimissing energy loss in hot rolling by intelligent manufacturing." European Commission, Research Fund of Coal and Steel. Tech Rep. UE-10-RFSR-CT-2010-00008, Dec 2013.

[3] Chen, C. S., Y. D. Lee, C. T. Hsu, D. S. Ting, C. C. Shen, "Power Quality Assessment of a Hot Strip Mill with Cycloconverter Drive Systems," Industry Applications Conference 2007, 42 ${ }^{\text {nd }}$ IAS Annual Meeting, pp. 9-16, Sept. 2007, New Orleans LA.

[4] H. Hosoda, S. Kodama, R. Tessendorf "Large PWM Inverters for Rolling Mills" Association for Iron \& Steel Technology Digital Library January 2008.

[5] A. K. Chattopadhyay, "Alternating Current Drives in the Steel Industry, Advancements in the last 30 years," Industrial Electronics Magazine, vol 4, pp. 30-42, December 2010.

[6] A. B. Nassif, W. Xu, "Passive Harmonic Filters for Medium-Voltage Industrial Systems: Practical Considerations and Topology Analysis," $39^{\text {th }}$ North American Power Symposium NAPS 2007, Sept. 2007 pp. 301307, Las Cruces NM.

[7] J. K. Phipps "A Transfer Function Approach to Harmonic Filter Design" Industry Applications Magazine, vol. 38, no. 2, pp. 68-82, March/April 1997.

[8] MathWorks, 2010, The MathWorks-MATLAB and Simulink for Technical Computing [Online]. Available: http://www.mathworks.com

[9] Wolfgang Timpe, "Cycloconverter Drives for Rolling Mills" IEEE Trans. on Industry Applications, vol. IA-18, no. 4, pp. 400-404, July/August 1982.

[10] J. R. Rodríguez, J. Pontt, P. Newman, R. Musalem, H. Miranda, L. Morán, G. Alzamora, "Technical Evaluation and Practical Experience of High-Power Grinding Mill Drives in Mining Applications" IEEE Trans. on Industry Applications, vol. 41, no. 3, pp. 866-873, May/June 2005.

[11] AISI/SAE Standard (American Iron and Steel Institute / Society of Automotive Engineers). SAE J403 1010. June 2014.

[12] AISI/SAE Standard (American Iron and Steel Institute / Society of Automotive Engineers). SAE J403 1012. June 2014.

[13] AISI/SAE Standard (American Iron and Steel Institute / Society of Automotive Engineers). SAE J403 1050. June 2014.

[14] J. L. E. Berciano, E.T. Guerra, S. E. de Bengy, D. F. Segovia "Laminación. Monografías sobre Tecnología del Acero. Parte IV" Madrid, pp 36-49, January 2010.

[15] F. Yamada, K. Sekiguchi, M. Tsugeno, Y. Anbe, Y. Andoh, C. Forse, M. Guernier, T. Coleman "Hot Strip Mill Mathematical models and SetUp Calculation,". IEEE Trans. on Industry Applications, vol. 27, no. 1, pp. 131-139, January/February 1991.

[16] U. Lotter, H.-P. Schmitz, L. Zhang, "Application of the Metallurgically Oriented Simulation System "TKS-StripCam" to predict the properties of Hot Strip Steels from the Rolling Conditions," Advanced Engineering Materials," vol. 4, Issue 4, pages 207-213, April, 2002.

[17] Mikell P. Groover "Fundamentals of Modern Manufacturing. Materials, Processes and Systems" John Wiley \& Sons, $4^{\text {th }}$ edition, pp. 395-403, 2010.

[18] "ASM Metals Handbook, vol. 14, Forming and Forging," ASM International, pp 351-355, 1996.

[19] J. M. D. Murphy, F. G. Turnbull "Power Electronic Control of AC Motors" Pergamon Press, pp 199-216, 1989.

[20] P. Aravena, L.Morán, J. Dixon, J. Espinoza, O. Godoy “A New Hybrid Filter Topology for Sub and Inter-harmonic Attenuation in Cycloconverter-Fed Drives Applications" Industry Applications Society Annual Meeting 2009, IAS 200, 4-8 Oct 2009, Houston, Texas.

[21] B. R. Pelly, Thyristor Phase-Controlled Converters and Cycloconverters. Hoboken, NJ, USA: Wiley-Interscience, 1971. 
[22] P. Aravena, L. Morán, R. Burgos, P. Astudillo, C. Olivares, and D. A. Melo "High-Power Cycloconverter for Mining Applications: Practical Recommendations for Operation, Protection, and Compensation" IEEE Trans. on Industry Applications, vol. 51, no. 1, pp 82-91, January/February 2015.

[23] S. G. Bosga, J. L. Duarte, A. J. Vandenput, "Natural Circulating Current Control of a Cycloconverter," Industry Applications Society Annual Meeting, 1993.Conference Record of the 1993 IEEE, pp. 1160 - 1165, vol 2, October 1993 Toronto, Ont.

[24] S. Tanaka, "Control Method for Cycloconverter and control Apparatus Therefor," U. S. Patent 4,670,826. Jun, 2, 1987.

[25] "IEEE Recommended Practices and Requirements for Harmonic Control in Electrical Power Systems" IEEE Std 519-2014, 2014.

[26] G. A. Orcajo, J. Rodríguez D., P. Ardura G., J. M. Cano, J. G. Norniella, R. Llera T., D. Cifrián R. "Dynamic Estimation of Electrical Demand in Hot Rolling Mills" IEEE Industry Applications Society Annual Meeting 2015, 18-22 Oct 2015 ,Dallas, Texas.

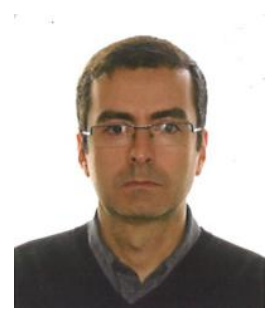

Gonzalo A. Orcajo was born in Gijón, Spain in 1965 . He received the M. Sc. and $\mathrm{Ph}$. D. degrees in electrical engineering from the University of Oviedo, Spain, in 1990 and 1998, respectively.

In 1992, he joined the Department of Electrical Engineering, University of Oviedo, where he is currently an Associate Professor. His main research interests are in the field of power quality in industrial power systems. In recent years, he has focused on the detection and location of faults in distribution systems and on reactive power compensation systems.

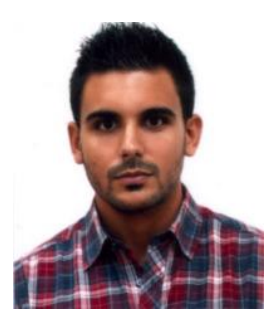

Josué Rodríguez D. was born in Pravia, Spain, in 1989. He received the M. Sc. in electrical engineering from the University of Oviedo, Spain in 2014.

He worked as a research fellow at the Department of Electrical Engineering of the University of Oviedo between October 2013 and June 2015. In July 2015, he joined the Department of Beams-RadioFrequencyPower amplifiers and Modules production (BE/RF/PM) at European Organization for Nuclear Research (CERN), Geneva, Switzerland. He works on the construction and commission of electronic test benches for future medical applications. His main research interests are in the field of reactive power compensation systems and power quality.

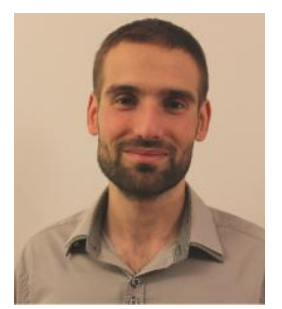

Pablo Ardura was born in Luarca, Spain, in 1986. He received M.Sc. degree in electrical and electronic engineering from the University of Oviedo, Spain, in 2010. $\mathrm{He}$ is currently pursuing the Ph.D degree in electrical engineering. From 2010 to 2014 he worked at the Department of Electrical Engineering of the University of Oviedo. In 2015 he joined the ArcelorMittal Global R\&D Center in Asturias, where he is currently working as a research engineer. His main research interests are in the field of power quality, power converters, energy storage and waste-heat recovery systems for the steelmaking industry.

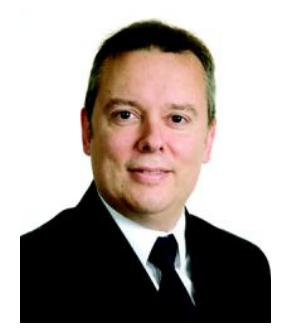

José M. Cano (M'98) was born in Oviedo, Spain, in 1971. He received the M.Sc. and Ph.D. degrees in electrical engineering from the University of Oviedo, Spain, in 1996 and 2000, respectively.

In 1996 he joined the Department of Electrical Engineering, University of Oviedo, where he is currently an Associate Professor. During 2012 he held an appointment as a Visiting Associate Professor at the Department of Electrical and Computing Engineering, University of British Columbia, Canada. His main research interests are in the field of power quality solutions for industry, power converters, distributed generation and smart grids.

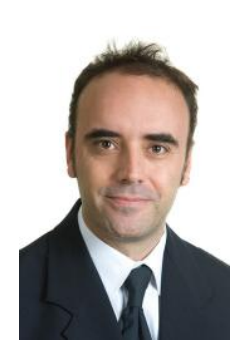

Joaquín G. Norniella was born in Gijón, Spain, in 1980. He received the M.Sc. and the $\mathrm{Ph} . \mathrm{D}$. degrees in electrical engineering from the University of Oviedo, Spain, in 2005 and 2012, respectively.

He worked as a research and development engineer at the Department of Electronic Engineering of the University of Oviedo for twenty months since February, 2007. In 2008 he joined the Department of Electrical Engineering of the aforementioned University, where he is currently working as a Lecturer. His main research interests are in the field of power quality solutions for industry and power converters.

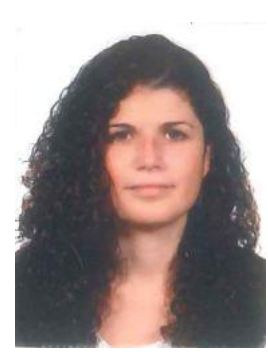

Rocio Llera was born in Oviedo, Spain, in 1983. She received the M.Sc degree in Forest \& Environment Engineering from the University of Oviedo, Spain, in 2006. She is currently pursuing the Ph.D degree in Mining, Civil Engineering and Project Management.

She worked as a research engineer at the Mining Exploitation Department of the University of Oviedo, for four years since 2006, on environmental and energy topics in the steel sector. In 2010 she joined ArcelorMittal, where she is currently working as $\mathrm{R} \& \mathrm{D}$ engineer in the Global R\&D Center in Asturias. She is involved in energy issues focused on process modeling, waste energy recovery and energy efficiency.

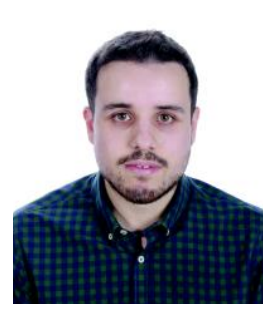

Diego Cifrián R. was born in Oviedo, Spain, in 1987. He received the M.Sc degree in electrical engineering from the University of Oviedo, Spain, in 2010.

In 2014 he joined ArcelorMittal, where he is currently working as an R\&D engineer in the Global R\&D Center in Asturias. His main research interest is in the field of innovative solutions for the steelmaking industry, focused on electrical and combustion process improvement. 